\title{
Pendampingan Integrasi Padi Itik pada Kelompok Tani Palem Desa Sumedangan Kabupaten Pamekasan Madura
}

\author{
Iswahyudi $^{1}$, Agus Budiyono ${ }^{2}$, Arin Wildani ${ }^{3}$ \\ ${ }^{1}$ Agroteknologi, Fakultas Pertanian, Universitas Islam Madura-JL.PP.Miftahul Ulum Bettet Pamekasan \\ ${ }^{2,3}$ Pendidikan Fisika, FKIP, Universitas Islam Madura-JL.PP.Miftahul Ulum Bettet Pamekasan \\ E-mail: iswahyudi.uim@gmail.com. No. HP 081935192468
}

\begin{abstract}
ABSTRAK
Kelompok tani Palem merupakan kelompok petani tanaman pangan yang berada di Desa Sumedangan Kecamatan Pademawu Kabupaten Pamekasan, yang mana desa tersebut merupakan wilayah aliran sungai. Lahan sawah dipinggiran sungai tersebut terkena dampak luapan air sungai, sehingga membanjiri lahan sawah petani setinggi $10-15 \mathrm{~cm}$. Dalam upaya peningkatan produksi padi pada penerapan integrasi padi itik dan peningkatan pendapatan kelompok tani menghadapi beberapa permasalahan. Diantaranya yaitu (1) mitra belum mendapat pengetahuan mengenai pola tanam padi terintegrasi dengan pemeliharaan itik, (2) mitra belum mempunyai tambahan penghasilan selain bertani, dan (3) mitra belum mengetahui bagaimana cara beternak itik dan memasarkan hasil ternak. Metode untuk mengatasi permasalahan mitra dilakukan dengan penyuluhan, pelatihan dan pendampingan aplikasi integrasi padi itik. Hasil diseminasi teknologi di lapang yang telah dilaksanakan diperoleh hasil sebagai berikut : 1) Kelompok tani "Palem" sangat antusias dan menguasai sistem integrasi padi itik ini karena dapat meningkatkan pertumbuhan serta produksi padi. 2) Peningkatan produksi padi mencapai 50\% dan 3) Mendapatkan penghasilan tambahan dari penjualan itik hasil integrasi.
\end{abstract}

Kata kunci : integrasi; padi; itik; jajar legowo

\begin{abstract}
The village of Sumedangan, Pademawu, Pamekasan, is a watershed. The rice fields there are including wetlands. These conditions are suitable for implemententing the integration of duck rice. The program partner is the farmers group "Palem". The problems solve in this program are (1) partners have not received knowledge about rice planting patterns integrated with duck maintenance, (2) partners do not have additional income other than farming, and (3) partners do not yet know how to raise ducks and market livestock products. The method used to solve partner problems are counseling, training and mentoring. The results of the dissemination of technology in the field that has been carried out obtained the following results: 1) The farmer group "Palem" was very enthusiastic and mastered the integration system of this duck rice because it could increase the growth and production of rice. 2) Increasing rice production reaches $50 \%$ and earns additional income from the sale of integration ducks.
\end{abstract}

Keywords : integration; rice; duck; jajar legowo.

Cara Mengutip : Iswahyudi, Budiyono, A., Wildani, A. (2019). Pendampingan Integrasi Padi Itik pada Kelompok Tani Palem Desa Sumedangan Kabupaten Pamekasan Madura. JAST: Jurnal Aplikasi Sains dan Teknologi, 3 (2), 96-101. doi:http://dx.doi.org/10.33366/jast.v3i2.1410 


\section{PENDAHULUAN}

Desa Sumedangan Kecamatan
Pademawu Kabupaten Pamekasan
merupakan wilayah aliran sungai. Lahan
sawah dipinggiran sungai tersebut terkena
dampak luapan air sungai ketika musim
penghujan datang, sehingga membanjiri
lahan sawah petani setinggi 10-15 cm.
Lahan sekitar sungai yang tadinya lahan
kering berubah menjadi lahan basah.
Lahan kering atau basah menjadi media
tumbuh tumbuhan secara konvensional.
Pada lahan kering kebutuhan tanaman
dapat tersedia dengan baik dibandingkan
dengan lahan basah. Lahan basah menurut
istilah bahasa Inggris adalah wetland,
dengan istilah lain merupakan lahan /
areal seperti rawa atau paya yang dapat
sewaktu-waktu tergenang oleh air namun
dangkal atau lahan dengan kondisi tanah
dengan genangan air[1].

Lahan basah saat tergenang air, memiliki kondisi tanahnya yang tidak ideal bagi tanaman. Tanah Pada lahan basah, memiliki unsur yang kurang lengkap. Adapun bagian-bagian tahan yaitu memiliki bagian padat, bagian cair, dan bagian udara yang berimbang merupakan ciri tahan ideal. Pada satu sisi lahan basah memberikan kerugian pada petani, namun disisi lain memberikan keuntungan. Keuntungan lahan basah yaitu menjadi alternatif lahan yang dapat dimanfaatkan sebagai lahan produksi pertanian yang produktif. Namun beberapa kendala yang akan dihadapi dalam merubah lahan-lahan tersebut menjadi produktif.

Mengingat kondisi lahan basah yang marjinal dan rapuh, maka dalam mengembangkan lahan basah memerlukan perencanaan, penanganan dan perbaikan yang teliti. Maka dari itu, integrasi suatu kajian perlu dilakukan yang mencakup inventarisasi kondisi lahan, pencarian komoditas dan varietas yang toleran serta perbaikan struktur masyarakat [2].

Pengembangan lahan basah wajib memperhatikan kondisi sumberdaya hayati lokal, sehingga dapat mendukung ekosistem tersebut. Pada umumnya lahan basah Desa Sumedangan dimanfaatkan petani untuk menanam padi, namun perlu perlakuan khusus pada tanaman padi yang ditanam pada lahan basah, antara lain harus siap memompa air keluar lahan dan tak kalah pentingnya adalah petani yang harus siap mengganti tanaman padi yang mati ketika baru tanam karena tidak tahan terhadap lahan yang terlalu basah. Akibat terjadinya banjir saat musim penghujan yang menyebabkan air sungai meluap pada lahan sawah padi sehingga terjadi penurunan hasil panen padi petani.

Berdasarkan hasil wawancara dengan mitra, mitra menginginkan kenaikan produksi padi pada lahan basah dan memiliki penghasilan tambahan selain menanam padi. Maka dari itu inovasi produksi padi terintegrasi dengan memelihara itik cocok untuk diterapkan pada lahan basah. Inovasi tersebut direspon mitra dengan antusiasme yang tinggi. Namun mitra masih kebingungan bagaimana penerapan inovasi tersebut.

\section{Permasalahan Mitra:}

Dari hasil diskusi di lapang untuk mengaplikasikan integrasi padi itik, kelompok tani Palem mempunyai beberapa kendala yaitu: 
a. Belum mendapat pengetahuan mengenai pola tanam padi terintegrasi dengan pemeliharaan itik.

b. Belum mempunyai tambahan penghasilan selain bertani.

c. Belum mengetahui bagaimana cara beternak dan memasarkan hasil ternak.

Oleh karena itu maka perlu diberikan dorongan, bimbingan dan pendampingan bagi kelompok tani Palem Desa Sumedangan agar kelompok tani nantinya dapat mandiri menjalankan program integrasi padi itik.

\section{METODE KEGIATAN}

$\begin{array}{lcr}\text { Sebagai langkah tepat } & \text { untuk } \\ \text { menyelesaikan } & \text { permasalahan } & \text { mitra } \\ \text { tersebut, tim } & \text { pelaksana } & \text { Program }\end{array}$
Kemitraan Masyarakat (PKM), melakukan beberapa tahapan program sebagai berikut:

1. Penyuluhan, Pemaparan dan Diskusi

Dalam penyuluhan ini, tim pelaksana PKM memberikan penyuluhan mengenai inovasi sistem jajar legowo tanam padi yang terintegrasi dengan memelihara itik.

\section{Pendampingan Terhadap Mitra}

Pendampingan ini merupakan, proses yang cukup panjang dalam menjalankan program PKM ini, pendampingan diawali dengan praktek penanaman jajar legowo padi, pembuatan kandang itik di sekitar lahan sawah, selanjutnya pengadaan bibit padi yang cocok dengan tanah basah, pengadaan pupuk, pengadaan anak itik dan pengadaan pakan itik
3. Partisipasi Mitra Dalam Pelaksanaan Program

Dalam pelaksanaan tim pelaksana PKM terus memantau perkembangan tanaman padi dan beternak bebek, agar apabila dalam program terjadi permasalahan seperti, padi dan/atau itik mati segera mendapat penanganan oleh tim pelaksana PKM. Tidak sampai disitu, tim PKM juga akan membantu memasarkan hasil dari ternak itik.

\section{KARYA UTAMA}

\subsection{Pelatihan sistem jajar legowo untuk mendukung integrasi padi itik}

Pelaksanaan teknis sistem integrasi padi itik diawali dengan penyuluhan mengenai sistem jajar legowo dan dilanjutkan dengan praktek penanaman jajar legowo 2 baris, menggunakan jarak tanam dalam barisan $15 \times 10 \mathrm{~cm}$ dan jarak tanam lorong (legowo) $30 \times 10 \mathrm{~cm}$, padi yang ditanam adalah varietas Ciherang. Berikut pelaksanaan penyuluhan dan praktek jajar legowo pada Kelompok Tani Palem Desa Sumedangan dapat dilihat pada Gambar 1

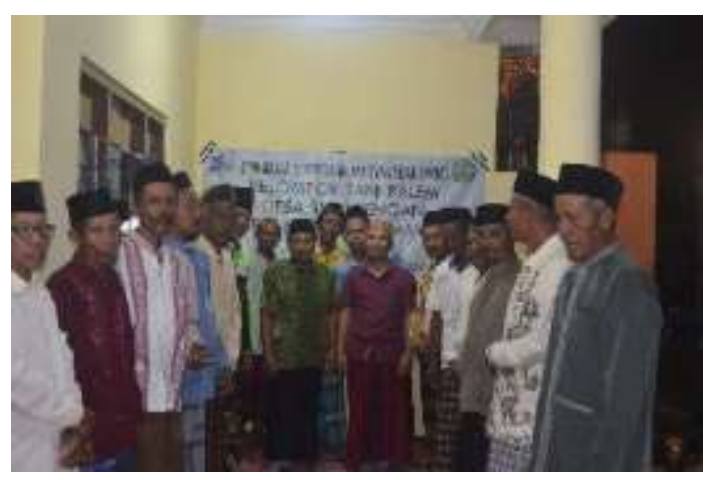

A 


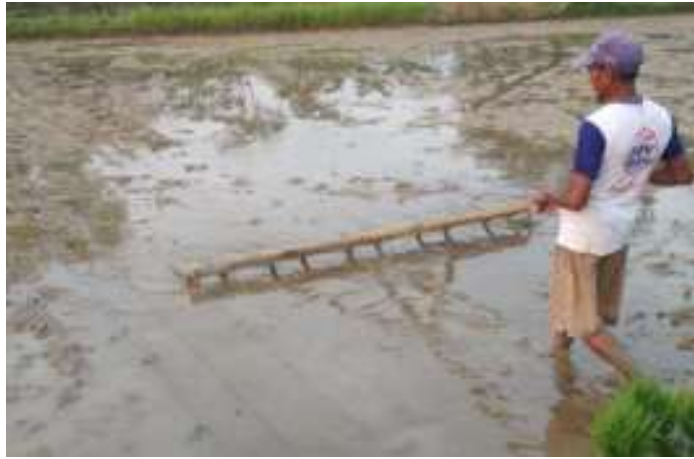

B

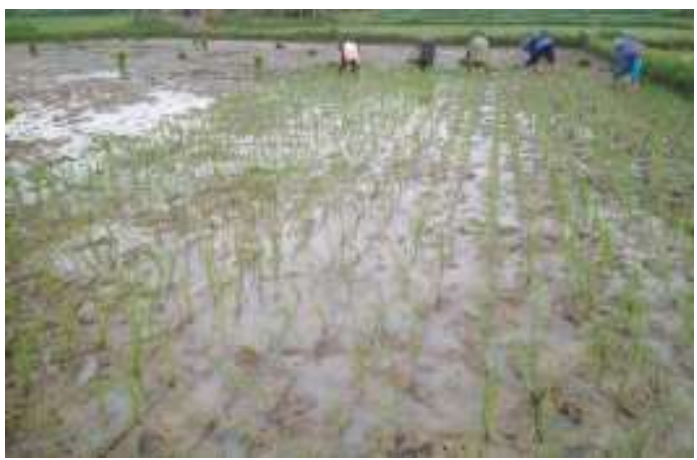

C

Gambar 1. Pelatihan sistem jajar legowo. (A) Dokumentasi penyuluhan, (B) Dokumentasi praktek menggaris lahan sistem jajar legowo, (C) Praktek menanam jajar legowo

\subsection{Pelepasan itik}

Budidaya itik secara terpadu dimulai saat perakaran tanaman padi

sudah mulai kuat, yaitu dua minggu setelah tanam, anak itik berumur 14 hari dilepas dalam areal sawah.

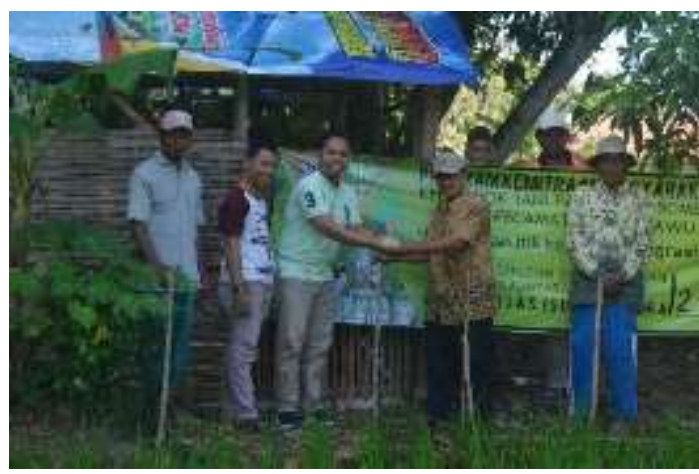

A

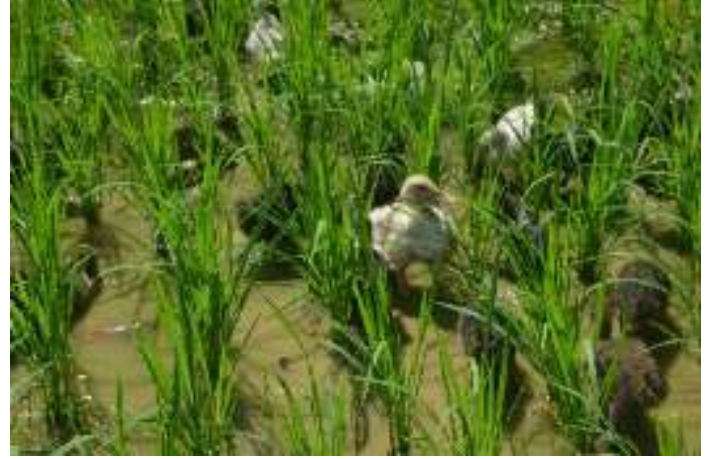

B

Gambar 2. Pelepasan Itik. (A) Dokumentasi pelepasan itik,

\section{ULASAN KARYA}

\subsection{Penyuluhan}

Dalam penyuluhan ini kelompok tani diberi pemahaman tentang tanam padi dengan sistem jajar legowo, adapun tujuan utama dari sistem tersebut adalah untuk meningkatkan populasi tanaman dengan cara mengatur jarak tanam dan memanipulasi lokasi dari tanaman. Dengan sistem tersebut para petani dapat dengan mudah menjelajahi tanaman padi hingga ke tengah karena sudah diatur jalur untuk jalan baik pada saat petani mau memberikan pupuk maupun mencabut rumput dan lainnya. Berdasarkan penilaian empat parameter kemampuan peserta yaitu Knowledge, Attitude, Skill dan Hasil Pretest/Post Test mengalami peningkatan yang baik dan signifikan terhadap kemampuan mitra PKM (Gambar 3).

Selain dengan penyuluhan tanam padi dengan sistem jajar legowo, kelompok tani juga diberikan penyuluhan tentang berternak itik yang diintegrasikan pada lahan tanaman padi. Metode berternak semacam ini menjadi metode 
yang baru dan belum pernah dilakukan pada kelompok tani. Dengan adanya metode integrasi ini maka petani selain mendapatkan hasil tani juga dapat memanen ternak itik yang lahan ternaknya menyatu dengan lahan pertanian.

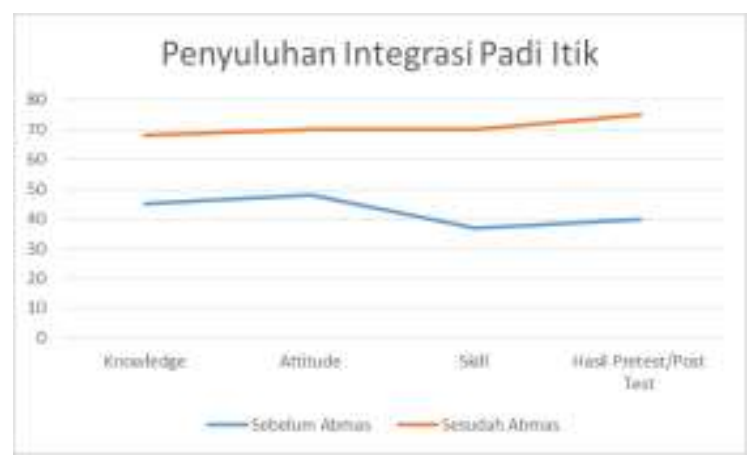

Gambar 3. Grafik penyuluhan integrasi Padi Itik

\subsection{Pendampingan}

Pada tahap pendampingan ini, kelompok tani didampingi baik pada saat praktek menggaris lahan sistem jajar legowo sekaligus praktek menanam jajar legowo. Dalam praktek ini kelompok tani berperan aktif sebagai hasil dari pengetahuan yang telah diberikan sebelumnya. Kelompok tani menggaris dan menanam padi seperti yang telah dijelaskan serta mendapat pendampingan dalam pelaksanaan praktek.

Selanjutnya, setelah akar padi menguat maka dilaksanakan pelepasa ituik ke lahan dan perawatan itik sampai siap panen. Dalam pendampingan ini kelompok tani selalu diawasi baik dalam pemupukan lahan padi maupun pemberian takaran pakan ternak itik. Yang paling dititikberatkan adalah pakan ternak dikurangi porsinya karena itik mendapatkan asupan makanan dari lahan, baik dari rumput maupun tanaman gulma. Sehingga dengan adanya integrasi padi itik ini, kelompok tani mendapatkan hasil panen yang melimpah yaitu panen dari padi dan juga panen dari itik.

Sejalan dengan budidaya padi sawah dengan sistem jajar legowo, banyaknya permintaan daging itik yang cukup tinggi maka dengan adanya petani yang memelihara itik akan memberi dampak positif bagi petani. Peluang sangat besar untuk meningkatkan nilai tambah, dapat dilakukan dengan pemeliharaan terpadu itik dan padi. Penanaman dengan sistem jajar legowo akan memberikan ruang yang cukup luas bagi itik untuk beraktivitas terutama untuk mencari makan [3]. Berdasarkan penilaian empat parameter kemampuan peserta yaitu Knowledge, Attitude, Skill dan Hasil Pretest/Post Test pada pendampingan integrasi padi itik mengalami peningkatan yang positif walaupun tidak signifikan terhadap kemampuan mitra PKM (Gambar 4).

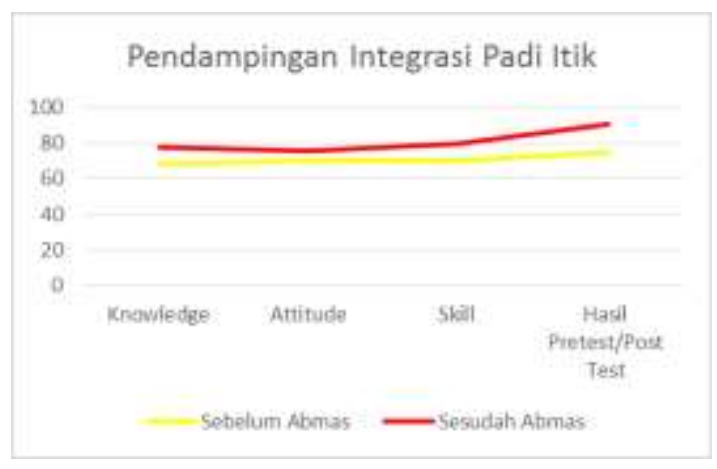

Gambar 4. Grafik pendampingan integrasi Padi Itik.

\section{DAMPAK DAN MANFAAT KEGIATAN}

Keunggulan inovasi teknologi integrasi itik/bebek dengan padi sawah ini adanya tambahan keuntungan dari pemeliharaan itik dibandingkan jika hanya menanam padi saja. Adapun keunggulan 
itik /bebek antara lain cepat tumbuh, kandungan lemaknya rendah dengan tekstur daging empuk dan gurih. Itik/bebek mempunyai pertumbuhan yang cepat, pada umur 70-75 hari berat badan mencapai 2-3 kg. Harga jual itik juga lebih tinggi yaitu Rp.60.000, - Rp.80.000.

Keuntungan yang diperoleh dengan adanya itik/bebek di sawah antara lain membantu pemupukan dari kotoran yang dihasilkan, meningkatkan kadar oksigen dalam tanah karena aktivitasnya dan meminimalkan rumput, gulma maupun hama (serangga, siput, keong mas) karena dimakan itik [4]. Sedang pakan untuk itik dapat dikurangi karena sudah mendapat pakan tambahan dari rumput, gulma, serangga, siput, keong mas dari sawah [5].

\section{KESIMPULAN}

Dari hasil kegiatan integrasi padi itik pada kelompok tani "Palem" Desa Sumedangan Pamekasan dapat disimpulkan sebagai berikut:

1) Kelompok tani "Palem" sangat antusias dan menguasai sistem integrasi padi itik ini karena dapat meningkatkan pertumbuhan serta produksi padi.

2) Peningkatan produksi padi mencapai $50 \%$ dan mendapatkan penghasilan tambahan dari penjualan itik hasil integrasi.

\section{PENGHARGAAN}

Terimakasih disampaikan kepada KEMENRISTEKDIKTI yang telah mendanai kegiatan ini melalui hibah Program Kemitraan Masyarakat (PKM) tahun anggaran 2019.

\section{DAFTAR PUSTAKA}

[1] Suwignyo, R.A. (2007). Ketahanan Tanaman Padi Terhadap Kondisi Terendam: Pemahaman Terhadap Karakter Fisiologis Untuk Mendapatkan Kultivar Padi Yang Toleran Di Lahan Rawa Lebak. Disajikan pada Kongres Ilmu Pengetahuan Wilayah Indonesia Barat. Palembang 3-5 Juni 2007.

[2] Suwignyo, R.A., Marsi dan D. Saputra. (1993) Pengembangan pertanian terpadu rawa lebak di Propinsi Sumatera Selatan. Makalah disajikan pada pertemuan antara Dewan Riset Nasional dengan Sivitas Akademika Universitas Sriwijaya. Gedung Seminar Unsri, Palembang 13 Juli 1993.

[3] Bakrie, B., Suwandi dan Simanjuntak, L. (2005). Prospek Pemeliharaan Terpadu "Tiktok" dengan Padi, Ikan dan Azolla di Wilayah Provinsi DKI Jakarta. Wartazoa Vol 15 No 3 : 128135.

[4] Suwandi, Dini A. (2011) Sistem Integrasi Pemeliharaan itik / Tiktok dan Tanaman Padi pada Lahan Sawah. Balai Pengkajian Teknologi Pertanian. Jakarta.

[5] Polakitan D, Mirah AD, Elly FH, Panelewen VVJ. 2015. Keuntungan Usahatani Padi Sawah Dan Ternak Itik Di Pesisir Danau Tondano Kabupaten Minahasa. Zootrek Journal. Vol. 35 No. 2 : 361-367. 